\title{
Integrated approach of the entrepreneurial behaviour in the tourist sector from disadvantaged mountain areas from Romania
}

\author{
Nicoleta Cristache ${ }^{1} \cdot$ Ionica Soare ${ }^{2} \cdot$ Marian Nastase $^{3} \cdot$ Valentin Marian Antohi $^{1}$ (D
}

Received: 6 January 2020 / Accepted: 19 July 2021 / Published online: 28 July 2021

(c) The Author(s), under exclusive licence to Springer Nature B.V. 2021

\begin{abstract}
The economic development of the tourism in disadvantaged mountain areas has the role of sustaining their development and economic growth. The premise of a successful development of tourism in these areas is given by the authenticity of resources. This paper aims to highlight the strategic perspectives/outlook of tourism in disadvantaged mountain areas through the evaluation of strategic alternatives using the concerted analysis SWOT-AHP. The aim of this study is to support communities and actors involved in the phenomenon of tourism in disadvantaged mountain areas in order to achieve positive results and as much as possible with awareness and avoidance of risks, and prevention or combating negative consequences. During the research and analysis, in accordance with the literature, the issue of entrepreneurship was treated as a dependent variable, and the phenomenon of tourism as an independent variable. The vision of tourism planning in disadvantaged mountain areas must focus on its sustainable development that contributes to increasing entrepreneurial initiatives by diversifying and ensuring the complementarity of tourism services calibrated to the needs of tourists and adapted to new social challenges. The strategic planning in the area of the tourism of disadvantaged mountain areas represents a topical challenge in the context of promoting sustainable tourism. Currently, there is a strategy at national level for developing tourism, but there is no strategy for developing tourism in disadvantaged mountain areas.
\end{abstract}

Keywords Sustainable tourism · Entrepreneurship · Disadvantaged mountain areas · Strategic alternatives $\cdot$ SWOT-AHP

\section{Introduction}

The intense global concerns about economic development in disadvantaged mountain areas have also generated a number of initiatives in Romania to stimulate processes that define this framework starting from the dynamics of different sectors: tourism, woodworking, craft activities, livestock farming, etc.

Valentin Marian Antohi

valentin_antohi@yahoo.com

Extended author information available on the last page of the article 
Starting from the capacity of small entrepreneurs who work in disadvantaged mountain areas to enhance existing value chains and create new ones, it is highly required that the role and impact of entrepreneurial behaviour be taken into account in the formulation of strategies as a factor that can favour the transition from subsistence entrepreneurship to the performing one.

In this context, the entrepreneurship can be considered a challenge with strategic potential as long as the efficient and sustainable use of resources in these areas is facilitated by the worldwide tourism sector actual trends, because it can generate new jobs and provide a varied range of products on a dynamic market. In order to generate the desired results, the appropriate conditions for a culture and a pattern of entrepreneurial behaviour must be created for what the entrepreneurial identity from disadvantaged mountain areas means.

In this paper, the analysis of the natural environment and especially the existing resources in these areas that can provide multiple possibilities of recreation and entertainment was pursued, amid the increase in recreation activities level sand tourism requested by tourists in the country and abroad, as well as the implications of these activities for the entrepreneurship associated with the mountainous tourism. Thus, a system is aimed to deal with the challenges of planning and managing the existing resources associated with the more diverse needs of the local tourists and especially the foreign ones. The planning and managing the tourism in disadvantaged mountain areas should take into consideration and include their specific features. Thus, the strategic alternatives proposed in this paper not only help developing an integral outlook regarding the entrepreneurship process-planning and managing the mountain tourism, but also extends the limits of research in the areas with features similar to mountain areas, mountain-specific facilities and entertainment.

The outcome of the present research has highlighted the fact that the entrepreneurship from disadvantaged mountain areas needs initiatives that should be integrated within a system which contributes to the sustainability of business. The whole research has been structured on four sections that refers to the theoretical markers from specialized literature regarding tourism and its issues, the actual framework of the tourism in disadvantaged mountain areas from Romania, the research methodology followed by the presentation results and the implication of these approaches for the entrepreneurial behaviour and in the end conclusions and possible directions of future researches.

Many tourist destinations from disadvantaged mountain areas in Romania must promote ecotourist initiatives in order to alleviate the problems connected with the subsistence environment and entrepreneurship. From the beginning, the ecotourism concept is credited because it will favour responsible tourist behaviour, preserving important habitats and ecosystems from the wild environment and will allow the promotion of the local cultures and traditional lifestyle and of sustainable way of living for the people who live in these areas.

\section{Literature review}

The mountain tourism is a concept-term that appeared in the context of new challenges of the tourism industry supported by the tourists' behaviour and preferences. As a tourist activity, the mountain tourism unfolds within the mountain area characterized by distinct elements of landscape, climate, wildlife, types of activities, traditions, local communities, etc. At present, the mountain tourism presents a high potential of stimulating economic growth both at local and national levels generated by complementarity 
relationships with other economic activities and the ability to promote the dispersion of tourist demand on a wider area (Crouch and McCabe, 2003).

The mountain tourism takes into account six specific characteristics of mountainous areas, namely: diversity, marginality, access difficulty, fragility, niche and aesthetics (Saarinen, 2004). This set of elements is able to increase the attractiveness of mountain areas and to contribute to their development.

The economic development of mountain areas through tourism represents a complex process because we must take into consideration on the one hand the diversity of resources and on the other hand the profile of the interested parts involved. The mountain tourism depends on a wide range of natural resources alongside with the elements of infrastructure, cultural resources of the area, accommodation, meal and entertainment services. If this system is not integrated and does not function properly, it can affect the tourist attractiveness of the area, the tourist demand and the economy of the area (Holden, 2003; Lane, 1994; MacDonald and Jolliffe, 2003). In this context, the analysis of mountain tourism from disadvantaged areas in the context of sustainability is much more complex (Garrod \& Fyall, 1998; Hardy et al., 2002). The lack of an integrated approach of the strategy of tourism development in disadvantaged mountainous areas has been marked in different studies that grasp complex aspects at the level of the structures that support this niche tourism (Bramwell \& Lane, 1993; Getz \& Timor, 2005). The mountain tourism is based on concepts regarding the alternative development in which are involved not only the resources of the area but also the interested local parts (Inskeep, 1991; Pearce, 1994; Weaver, 2005).

Entrepreneurial behaviour is essential for the financial performance of tourism companies. In the field of tourism, entrepreneurial behaviour involves a combination of innovation, proactivity and risk-taking (Covin \& Slevin, 1986), related to both internal factors of companies (Wiklund \& Shepherd, 2005) and external factors, all influencing financial performance (Eggers et al., 2014).

According to the authors KirKuščer, Tanja Mihalič \& Harald Pechlaner (2016) in "Innovation, Sustainable tourism and environments in mountain destination development: a comparative analysis of Austria, Slovenia and Switzerland", managers in mountain destinations must focus on effective actions for sustainable development of mountain tourism using the results of comparison with similar mountain destinations (Murphy, 1983). This comparative context could provide a framework for a number of useful values leading to an increase in the sustainability of a destination.

At present, the greatest challenge is that of balancing the priorities as part of a process in which the strategic objective is to promote the principles of sustainability of tourism in disadvantaged mountain areas according to the need to really support the local and regional economy (Aronsson, 1994; Pigram and Jenkins, 1999; Štrukelj and Šuligoj, 2014). The rather high division of the market of mountain tourism involves costs of promoting and relating to other complementary industries that can finally lead to the recognition and strengthening of the market (Roberts and Hall, 2001; Carey et al., 1997; Friel, 1999; Fyall $\&$ Garrod, 2005). The cooperation within these sectors is a vector for strengthening the structure of mountain in tourism, and a functional network implies entrepreneurship initiatives, certifying traditional products, promoting local identity and traditions (Bramwell and Lane, 1993; O'Reilly, 1986).

Ensuring the sustainability of tourism in disadvantaged mountain areas can be achieved through the creation of new opportunities and the transition from subsistence entrepreneurship to a successful one through an integrated set of activities of identifying, monitoring, informing, educating and collaborating with other domains. 


\section{The actual framework of tourism in disadvantaged mountain areas from Romania}

The mountainous area of Romania, respectively, about $30 \%$ of the territory represents the least anthropically modified area, having a low density of stable population and small localities. In the mountainous regions, the weak anthropization fostered the appearance of the most important protected areas in our country, respectively, 12 of the 13 national parks and 9 of the 15 natural parks. The disparities between European and Romanian mountain areas are huge especially from the perspective of transport infrastructure development, public utilities, other types of infrastructure objectives, determined by the existence of a diversified economy and generating significant profit for local communities.

At present, the disadvantaged mountain area of Romania greatly corresponds to the Carpathian area, occupying a total surface of $71.340 \mathrm{~km}^{2}$, respectively, $29,93 \%$ from the total surface of Romania, and comprises 658 territorial administrative units in which about 2.400 .000 inhabitants live almost $11 \%$ from the total population of Romania.

The disadvantaged mountain area has large areas of natural meadows ( 2.1 million ha), most of them (60\%) with a high natural value, maintained in this condition, over time, through a traditional extensive agriculture.

Mountain tourism entrepreneurship can only be sustainable under the conditions of an integrated strategy, targeting the entire production cycle from their source to the final product promoted through an appropriate marketing policy. The mountain tourism product can save tourism from disadvantaged mountain areas in Romania, but for this, it needs adequate legislation, strategies at national, regional and local level, cooperation of entrepreneurs in associative structures, as well as a careful follow-up of a set of specific rules and regulations to ensure a fair competitive environment.

The existent natural conditions (mineral, thermal waters, picturesque and varied landscape) favourable to outdoor tourism (hiking, winter sports, cycling, mountaineering, equestrian tourism, active tourism, adventure tourism, ecotourism, wildlife observation, plants and nature in general, hunting and sport fishing, cultural tourism, etc.) can represent an opportunity to increase the income of mountain residents, but also for the economic development of regions dependent on large industries in the past. The development of tourism has not been achieved in a sustainable manner and most often has not been correlated with the development of transport infrastructure, services and leisure units. The tourism infrastructure is still poor in terms of tourist markings, mountain chalets, mountain tourist routes, resting places, camping areas or serving natural and historical monuments.

It can be said that these areas have a great economic, social, cultural and environmental potential, which needs a strategic approach that ensures in the future the increase in attractiveness and sustainable development of these areas through the capitalization of resources, maintaining cultural identity, the increase in economic power at local level, on the terms of maintaining the environmental balance and protecting the environment (Fig. 1).

As a matter of fact, through some strategic objectives' assumption in the domain of tourism the protection and responsible capitalization of mountain resources are achieved taking into account the climate changes, customs and the stabilization of population. An essential issue that defines the actual framework of these regions is the one referring to eliminate the difference regarding the development of the tourism in disadvantaged mountain areas and other areas from Romania and EU, regarding the income and living conditions.

Thus, mountain areas must benefit from a specific policy defined according to the principles of sustainable development that ensures the present needs without compromising 


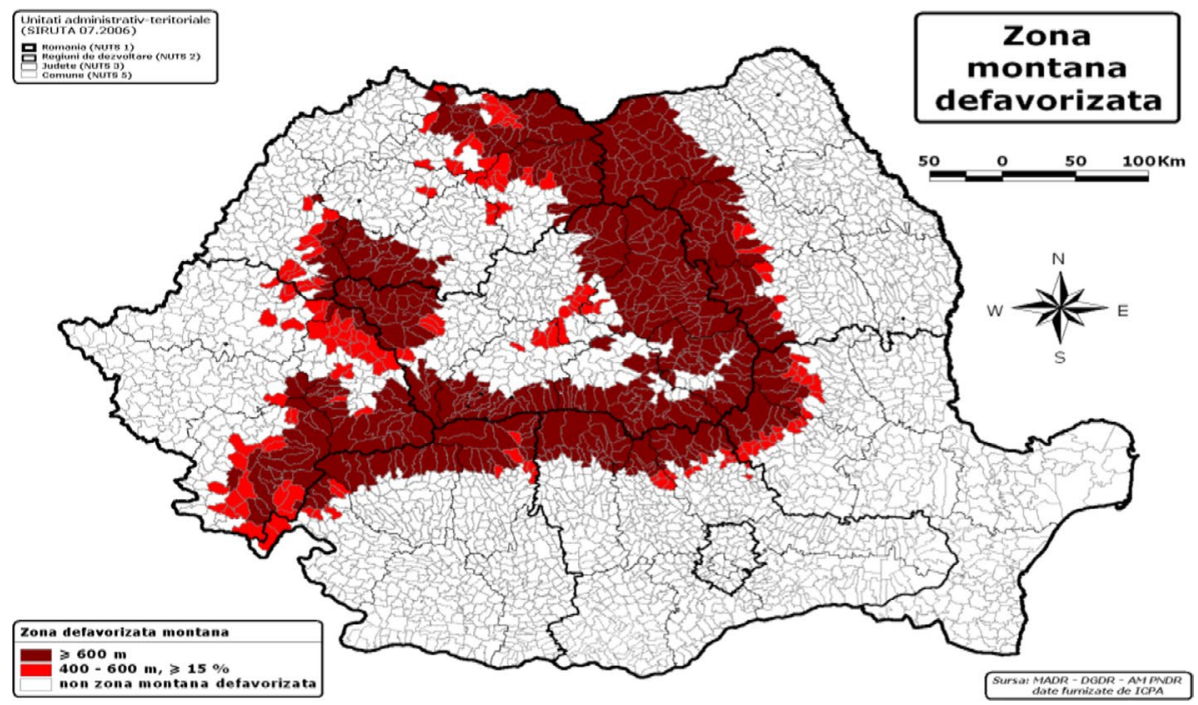

Fig. 1 Disadvantaged mountain areas from Romania. Source: http://www.apia.org.ro

the chances of future generations (Cooper, 2006). Moreover, the strategic directions aim at reducing the imbalance between more favoured and disadvantaged mountainous areas, marked by permanent natural constraints, different issues at economic, social, cultural and environmental plan. The entirety of decisions connected with the strategic options regarding tourism in mountain areas must ensure the framework for cooperation not only at local level but also at global level of all stakeholders.

In Romania, tourism entrepreneurship in disadvantaged mountain areas can take on a stronger dimension given that tourism reforms will continue. Further reform process from the perspective of what central and local authorities could do to encourage tourism entrepreneurship represents a significant premise. Thus, entrepreneurs in disadvantaged mountain areas can be connected to resources and markets outside their own community and thus can develop successful businesses. With proper support, ideas and people in these areas can be encouraged to reach the threshold needed to attract capital for investment. The use of information technology for the application of collaborative marketing strategies that can be sectoral or by geographical areas allows interaction and exchanges between entrepreneurs from different regions.

- There are still many opportunities to encourage innovation in mountain tourism. Rural tourism entrepreneurship represents a component of a real development perspective for disadvantaged mountain areas. Any successful strategy that targets disadvantaged mountain areas aims to promote the growth of that area. Basically, resources are no longer approached separately, but everything is integrated into a sustainable system.

- Entrepreneurial behaviour in the field of tourism involves a combination of innovation, proactivity and risk-taking (Peters \& Kallmuenzer, 2015), related to both internal factors of companies (Wiklund \& Shepherd, 2005) and external factors, all influencing financial performance (Eggers et al., 2014).

The disadvantaged mountain areas in Romania have the following characteristics (www.azm.gov.ro): 
- Poor infrastructure

- Low standard of living for the population in the area

- High degree of ageing population

- Large number of unemployed

- Reduced capitalization, from the tourist point of view, of the natural and anthropological resources of the area.

At present, the tourist structure of the disadvantaged mountain area is marked by an increase of 30\% of the number of accommodation units between 2014 and 2017, especially at the level of tourist and agritourist boarding houses (about 45\%). This increase has been generated by the process of accessing European non-refundable funds meant for tourism. Although the number of accommodation places has increased, the one of staying overnight has decreased by $6 \%$ the biggest decreases being recorded in the case of staying overnight in school camps, holiday villages, motels and hotels. An increase of $52 \%$ of staying overnight in agritourist boarding houses has been recorded. It must be mentioned that this development has not been achieved in an integrated and sustainable way, not being related to the development of tourist infrastructure, recreation services, the infrastructure of mountainous trail hallmarks, places of accommodation, mountain chalets, camping sites, etc. The existence of some attractive natural resources: mineral water, thermal waters, landscape and hunting fund leading to practicing various outdoor activities: hiking, winter sports, ciclotourism, mountain climbing, riding tourism, active tourism, adventure tourism, ecotourism, observing wildlife, plants and nature in general, recreational hunting and fishing, can be an opportunity for increasing the inhabitants' income from mountain area, but also for the economic development of the whole area.

In the actual context, the strategic directions regarding tourism must be in accordance with the three priority elements of the Strategy Europe 2020 that is: intelligent increase - the development of an economy based on knowledge and innovation; the sustainable increase-promoting a more ecological and competitive economy, which uses the resources more efficiently; and the inclusive increase-promoting an economy with high degree of occupation, which generates social and territorial cohesion. In the architecture of this strategic vision regarding the tourism from disadvantaged mountainous area, we must take into consideration the following:

- The increase in the attractiveness of disadvantaged areas and the stabilization of mountain population;

- The amelioration of the quality of environmental factors from disadvantaged mountain area and preserving the bio-diversity;

- The increase in economic competitiveness;

- Preserving and capitalization of cultural resources;

- Transition from the subsistence entrepreneurship to a pattern of performing entrepreneurship.

In fact, on this occasion, a great challenge is marked for the actual economy, respectively, the process through which the group of subsistence entrepreneurs manages to develop their business and experience to positively influence the subsistence communities in which they perform their activity.

According to the authors KirKuščer, Tanja Mihalič and Harald Pechlaner (2016), mountain destinations in disadvantaged areas have a great potential for development, and 
through the dynamic process of innovation, real opportunities can be identified that lead to sustainability.

It is known that the tourism industry is one of the most vulnerable industries to crises or disasters (Biggs et al., 2012; Hall, 2010). In the current context generated by the COVID19 pandemic, there should be a critical reconsideration of the global model of increasing the volume of tourism, for reasons related to the risks borne in global travel. Basically, new research topics will be generated as the pandemic will support nationalism and tighter borders in the long run, the role of domestic tourism will be emphasized, and many domestic destinations will be more sought after. Baldwin \& Weder di Mauro (2020). Specifically, the pandemic raises vulnerability issues, as low-wage jobs in tourism have been disproportionately affected by the crisis, and there are indications that the impact of tourism in lowerincome countries will be considerably disproportionately higher. The COVID-19 pandemic offers lessons about the effects of global change, for the tourism industry, decision-makers and tourism researchers. The challenge now is for everyone to learn from this global phenomenon to accelerate transformation of sustainable tourism. Bai et al. (2020).

Currently, entrepreneurs in the field of entrepreneurship believe that SMEs in the tourism sector are facing the biggest challenge in recent years. The challenge comes with both negative and positive aspects, which can turn into real opportunities for the Romanian tourism sector.

The pressure on the tourism industry is unprecedented as it faces a considerable reduction in the number of tourists from abroad but also from the country (Gössling and Michael Hal, 2020). Other related sectors, such as food services, cultural and entertainment activities, are also under increasing pressure due to the COVID-19 pandemic and efforts to limit its spread.

Disadvantaged areas in Romania face a variety of problems in this case as many companies have restricted or stopped their activities. According to official statistics, in Romania, three out of ten companies in Romania are at risk, with higher expenses than revenues, totalling 850,000 employees (one-fifth of the total number of employees in the private sector). In Romania, measures to support the SME sector reach a percentage of $2 \%$ of GDP, while in other countries the aid granted amounts to about $10 \%$ of GDP. The supports promoted by the Government for the companies that suspended the employees' contracts cover only a part of the salaries. In the context in which the state intends to reimburse, in whole or in part, the amounts paid as advances by tourists requesting this, the money can be allocated from European funds for areas affected by COVID-19, in the form of meal vouchers or vouchers for tourist services in Romania, valid until the end of 2021.

\section{The research methodology}

This study aims at analysing the relevant aspects regarding the entrepreneurial behaviour from disadvantaged mountain areas towards the substantiation of elements that can constitute landmarks in the elaboration of strategies for the development of the tourism in disadvantaged mountainous areas. Within this study, an online questionnaire has been used, containing 16 close topic questions and 5 questions for characterizing the sample; the questionnaire has been managed by Google Docs platform and the sample has been formed of entrepreneurs from disadvantaged mountainous areas. The data were collected from November to December 2019. The sample that was subject to research comprised 136 entrepreneurs with the following characteristics: 
- 46-entrepreneurs from the area of The Apuseni Mountains;

- 23-entrepreneurs from the mountainous area of Buzău;

- 32-entrepreneurs from the mountainous area of Sebeș;

- 35-entrepreneurs from the mountainous area of Vrancea.

According to the legal status of the firm, the sample contained 58 authorized individuals, representing 42.65\%, 36 family associations, representing $26.47 \%, 42$ associations with limited accountability, representing $30.88 \%$. As far as the activity sector characterizing the entrepreneurship from these areas is concerned, it can be seen that $67 \%$ of the firms operate in the tourism domain and public alimentation, $13 \%$ in trade and $10 \%$ in industry. From the category of those operating in the tourism domain, $47 \%$ of the firms perform their activity in rural tourism, $24 \%$ perform specific mountainous activity (exploitation, wood processing, furniture element) and $29 \%$ perform activities in trade and public alimentation. The obtained answers have been analysed from the perspective of substantiation a set of recommendations towards achieving a strategic planning in the domain of tourism in disadvantaged mountainous areas.

\subsection{Strategic orientations starting from the conjugated analysis SWOT-AHP for the tourism in disadvantaged mountain areas}

The mountain tourism from disadvantaged mountain areas can become not only an option but also a necessity for the Romanian tourist sector which intends to be more and more performing. In this section, the identified components within SWOT analysis are assessed using AHP method in order to proportion the force.

AHP is a method which allows taking complex decisions using more criteria for managing certain critical aspects of a problem structured in a hierarchical manner or solving some unstructured issues (Coyle, 2004). Applying AHP method, the best decision can be obtained along with a justification of the choices made through the presentation of the rate of criteria chosen in the final solution. This method is complex because it detects in a systematic approach not only quantitative but also qualitative aspects, and from their interaction, the final decision is drawn (Ayag, 2005). Thus, a complex issue will be decomposed into a hierarchical structure consisting of a purpose and a series of objectives, criteria allotted on different levels with alternative decisions that can be approached from the perspectives of pair comparisons. In this context, the method of pair comparison will allow the identification of alternative priorities existing at the analysed issue that requires taking a decision on multiple criteria. On top of the hierarchy of this study, there is the accessibility of disadvantaged mountainous areas for the entrepreneurial domain in touristic sector.

Within this section, the elements of SWOT analysis will be evaluated and prioritized according to the process of the method AHP, which can provide a quantitative measure of the significance of each factor. The SWOT analysis of the entrepreneurial framework of the tourism in disadvantaged mountainous areas through systematic approach and inclusive identification provides a first image of the offer and demand for the products of mountainous tourism in these areas. Obviously that after these images, the effects of different policies can be determined in the impact on the investments in these areas, fact highlighted through the process of analytical hierarchy (AHP). In fact, each factor from the four categories will be compared with the others, resulting in a crossed analysis from the criteria of investment preferred by the entrepreneurs who participated in the 
investigation. The final evaluation implied the determination of the rates for each strategic alternative using K software Goepel version 9.5.2012 (Table 1).

\subsubsection{The SWOT analysis of the tourism in disadvantaged mountainous areas}

The SWOT analysis is a tool used for the monitorization and simultaneous analysis of the internal and external environment in order to obtain a systemic approach and a support for decision situations. Through the application of SWOT analysis in the farreaching strategic decisional mechanisms, we seek to choose and apply a strategic version that will lead to the most appropriate match between the elements of the internal environment with the external one. The framework of SWOT analysis for the tourism in disadvantaged areas will be presented as follows:

Table 1 SWOT matrix

\begin{tabular}{|c|c|}
\hline Strengths & Weaknesses \\
\hline $\begin{array}{l}\text { S1-Attractive/unique/special resources } \\
\text { S2-The existence of local traditions and customs } \\
\text { S3-The preserved natural environment (wildlife) } \\
\text { S4-Great variety of tourist activities (hiking, winter } \\
\text { sports, climbing) } \\
\text { S5-The interest of local authorities and communities } \\
\text { in certain areas to attract investments and to ensure } \\
\text { the growth of economic well-being }\end{array}$ & $\begin{array}{l}\text { W1-Deficient infrastructure W2-The lack of } \\
\text { facilities for tourists (hallmarks, trails, accommo- } \\
\text { dation places, arranged chalets) } \\
\text { W3-The monitorization and mapping of the main } \\
\text { tourist attractions from disadvantaged mountain } \\
\text { areas } \\
\text { W4-The poor promoting of the destinations with } \\
\text { tourist potential in disadvantaged mountain areas } \\
\text { W5-The lack of an integrated strategy of the tour- } \\
\text { ism development from disadvantaged mountain } \\
\text { areas } \\
\text { W6-Generally rarefied and aged population } \\
\text { W7-Lack of a mass tourist education in the area }\end{array}$ \\
\hline
\end{tabular}

Opportunities

O1-Initiatives of local entrepreneurship

O2 - The development of other connected domains (skills, cuisine)

O3 - The increase in the interest in mountain area at world level (niche tourism)

O4-The preservation and promotion of the cultural heritage (the initiation of programme under the patronage of some national, international institutions/organizations)

O5-The certification of some local products

O6-The entry of tourist destinations from disadvantaged mountainous areas in circuits with high notoriety

O7-Making new workplaces

O8-The existence of European financed programmes, some of them ensuring funds for rural/ mountainous development

O9-The possibility of connecting the development of tourism from disadvantaged areas with other economic branches: transport, constructions, education, trade, services
Threats

T1-Lack of studies regarding the impact of tourism on the environment

T2-Weak investments in the tourism in disadvantaged mountainous areas

T3-The strong competition from other tourist areas

T4-Tourists' behaviour (comfort/convenience for certain accommodation/meal/recreation conditions)

T5-The lack of incentives for entrepreneurial initiatives in disadvantaged mountainous areas

T6-The impact on the natural resources in the area

T7-Difficult access to national/international financing (lack of information, deficient financial education, etc.)

T8-Relatively high investments to ensure the continuity of the flow of tourists along the four seasons 


\subsubsection{The conjugated analysis SWOT-AHP for the tourism in disadvantaged mountainous areas}

The AHP process is applied to SWOT matrix, and practically each respondents' preference is turned into a number value that can be compared and assessed on a scale from 1 to 9 . All the comparisons have been achieved following the processing of data gathered within the study, and the results are presented in Table 2.

Furthermore, local and global values of the elements of SWOT matrix are calculated in Table 3.

The need for an integrated approach of entrepreneurial behaviour is given by the systematic perspective on the sustainable development in the tourism sector which allows high lighting the influential elements from an economic, social and environmental point of view. Through this type of approach, an important basis can be offered for the elaboration of strategic alternatives where an innovative, responsible and sustainable entrepreneurial practice is promoted, respecting the principle of variety.

In this context, the critical connections between the entrepreneurial behaviour and tourism become objectives for the increase in the capacity of disadvantaged mountain areas to set up new businesses.

Starting from the theory of complexity, the pattern of entrepreneurial behaviour must be able to identify and exploit the existing opportunities in due course in order to efficiently manage the changes and risks associated with the domain.

This is possible through the orientation towards innovation, aspect that implies redesigning of the tourist products and their sharing within an integrated system of entrepreneurship not only horizontally but also vertically, which allows the accomplishment of programmes, projects campaigns with common objectives, respecting at the same time the specific feature, identity and values of each area.

Thus, an integrated pattern regarding the entrepreneurial process aims at achieving major objectives as follows: promoting the identity of the areas, economic development at the level of disadvantaged mountain areas and last but not least a sustainable mountain tourism. In this context, we will take into consideration the possibility of analysing five strategic alternatives with the following structure:

$\mathrm{S} 1$ - the monitorization strategy which implies a process of mapping, monitorization of local identity resources, the making of a brand for tourist destinations in disadvantaged mountain areas and their digitalization;

S2 - the strategy of informing which aims at accessing the information for programmes/ sources/opportunities of financing/partnerships for entrepreneurship;

S3 - the strategy of interaction concentrated on a wide process of communication and interaction with interested stakeholders-events, databases, projects;

Table 2 Pair comparisons between SWOT elements

\begin{tabular}{llllll}
\hline $\begin{array}{l}\text { SWOT ele- } \\
\text { ments }\end{array}$ & $S$ & $W$ & $O$ & $T$ & Rate \\
\hline$S$ & 1,000 & 2,000 & 0,500 & 0,250 & 0,380 \\
$W$ & 2,000 & 1,000 & 3,000 & 0,333 & 0.190 \\
$O$ & 0,500 & 3,000 & 1,000 & 0,500 & 0.290 \\
$T$ & 0,250 & 0,333 & 0,500 & 1,000 & 0.140 \\
$\mathrm{CR}=0,06$ & & & & & \\
\hline
\end{tabular}









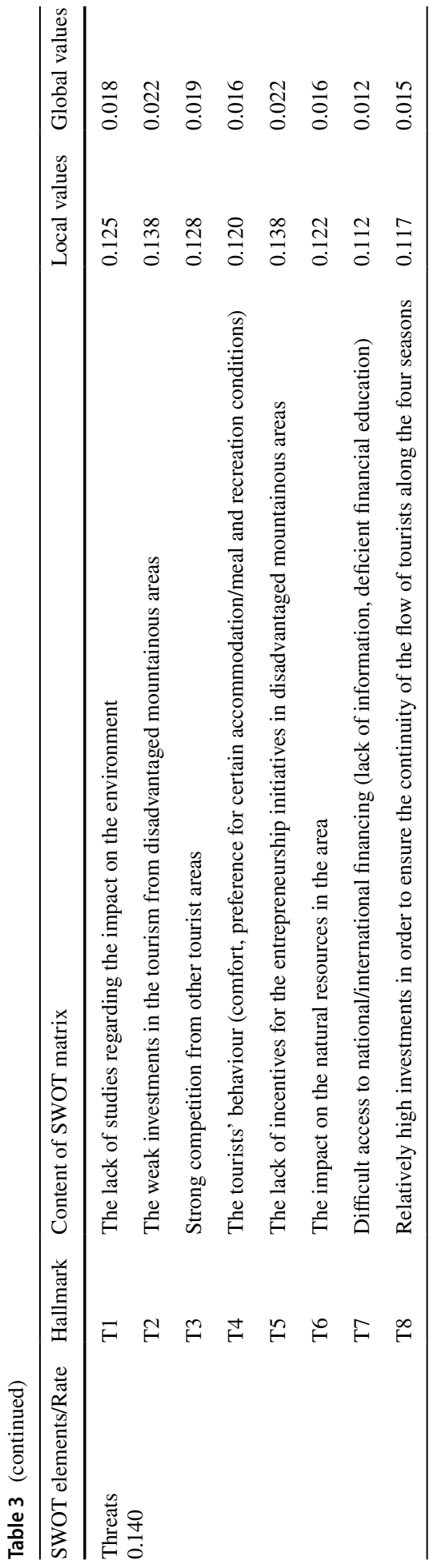


S4 - the strategy of development which seeks to implement campaigns of promoting tourist destinations in disadvantaged mountainous areas at national and international level;

S5-the strategy of integration which has as an objective a real process of integration both horizontally and vertically (within the tourist sector and other sectors).

The relationships between the elements of SWOT analysis and proposed strategic alternatives are presented in Table 4 according to the way they have been evaluated on a scale from 1 to 5 by entrepreneurs that took part in the research. The cumulative evaluation of the relationships between the strategic alternatives and the elements of SWOT analysis practically allowed the evaluation of these strategies. Through the AHP method, the value of the weight of the criteria from SWOT analysis has been determined.

The gradient of relations $\left(r_{i j}\right)$ represents the appreciation of the entrepreneurs questioned regarding the way in which each element from the SWOT quadrant can contribute or not

Table 4 The matrix of evaluating strategic alternatives (Source: processing authors with K. Goepel v. 9.5.2012. software)

\begin{tabular}{|c|c|c|c|c|c|c|c|c|}
\hline $\begin{array}{l}\text { SWOT } \\
\text { Elements }\end{array}$ & Hallmark & $K$ factor & Global values & S1 & S2 & S3 & S4 & S5 \\
\hline \multirow[t]{5}{*}{ Strengths } & S1 & 2 & 0,120 & 5 & 4 & 3 & 2 & 3 \\
\hline & S2 & 2 & 0,055 & 4 & 3 & 2 & 1 & 5 \\
\hline & S3 & 2 & 0,096 & 5 & 3 & 1 & 3 & 2 \\
\hline & S4 & 2 & 0,068 & 5 & 4 & 4 & 1 & 2 \\
\hline & S5 & 2 & 0,042 & 4 & 2 & 5 & 3 & 3 \\
\hline \multirow[t]{7}{*}{ Weaknesses } & W1 & 1 & 0,024 & 1 & 2 & 3 & 3 & 4 \\
\hline & W2 & 1 & 0,037 & 4 & 2 & 2 & 1 & 1 \\
\hline & W3 & 1 & 0,058 & 5 & 4 & 2 & 3 & 3 \\
\hline & W4 & 1 & 0,020 & 2 & 2 & 3 & 2 & 4 \\
\hline & W5 & 1 & 0,021 & 1 & 2 & 3 & 2 & 2 \\
\hline & W6 & 1 & 0,010 & 1 & 2 & 2 & 1 & 1 \\
\hline & W7 & 1 & 0,020 & 3 & 2 & 2 & 4 & 3 \\
\hline \multirow[t]{9}{*}{ Opportunities } & $\mathrm{O} 1$ & 2 & 0.053 & 2 & 2 & 3 & 3 & 5 \\
\hline & $\mathrm{O} 2$ & 2 & 0.038 & 2 & 3 & 2 & 5 & 4 \\
\hline & $\mathrm{O} 3$ & 2 & 0.024 & 1 & 2 & 4 & 5 & 3 \\
\hline & $\mathrm{O} 4$ & 2 & 0.028 & 5 & 2 & 2 & 3 & 1 \\
\hline & O5 & 2 & 0.024 & 3 & 3 & 2 & 2 & 4 \\
\hline & O6 & 2 & 0.041 & 2 & 2 & 4 & 3 & 3 \\
\hline & O7 & 2 & 0.030 & 1 & 2 & 4 & 3 & 2 \\
\hline & O8 & 2 & 0.032 & 1 & 1 & 3 & 2 & 3 \\
\hline & O9 & 2 & 0.020 & 1 & 2 & 3 & 2 & 2 \\
\hline \multirow[t]{8}{*}{ Threats } & $\mathrm{T} 1$ & 1 & 0.018 & 1 & 3 & 1 & 2 & 2 \\
\hline & $\mathrm{T} 2$ & 1 & 0.022 & 1 & 1 & 3 & 2 & 2 \\
\hline & $\mathrm{T} 3$ & 1 & 0.019 & 1 & 2 & 4 & 2 & 3 \\
\hline & $\mathrm{T} 4$ & 1 & 0.016 & 2 & 3 & 4 & 2 & 2 \\
\hline & $\mathrm{T} 5$ & 1 & 0.022 & 3 & 2 & 3 & 2 & 1 \\
\hline & T6 & 1 & 0.016 & 2 & 1 & 1 & 3 & 3 \\
\hline & $\mathrm{T} 7$ & 1 & 0.012 & 3 & 2 & 2 & 2 & 2 \\
\hline & $\mathrm{T} 8$ & 1 & 0.015 & 3 & 4 & 1 & 1 & 2 \\
\hline
\end{tabular}


to each strategic alternative and how they can be further integrated in order to establish an appropriate strategic version. The fingerprint of each element can be positive $(\mathrm{S}, \mathrm{O})$ or negative $(W, T)$ and contribute proportionally different to the global evaluation of strategic alternatives.

The values of strategic alternatives $\left(\mathrm{St}_{i}\right)$ have been calculated using the following expressions:

$$
\mathrm{St}_{i}=\sum_{j=1}^{n} w_{j} * r_{i j}(-1)^{k}
$$

$k$ can take the value 2 -for the elements from the quadrants $\mathrm{SO}$, and value 1 -for the elements from the quadrants WT, where $\mathrm{St}_{i}$ - the total value of the strategic alternative; $w_{j}$-the global weight of a $j$ element from the SWOT analysis; $r_{i j}$-the degree of the relationships between the strategic alternative $\mathrm{i}$ and $\mathrm{j}$ SWOT elements; $n$ - the number of the elements from the SWOT analysis; and $k$ - the factor of the positive and negative contribution of the elements from SWOT matrix.

The value of each factor for each strategic alternative can be multiplied, taking into account the global values of the elements of SWOT analysis and the degree of the relations with the SWOT elements (Table 5).

It can be observed that through the application of the calculation formula in order to quantify the impact of each strategic alternative, version S5-which implies horizontal and vertical integration not only within the tourist sector but also other sectors-is the most attractive for the entrepreneurs from the areas analysed. Even though the entirety of elements from SWOT analysis is not very high, the analysis of the strategic alternatives on the basis of the evaluation matrix is consistent. Pursuant to the evaluation of the strategic alternatives, the following correlations have been obtained:

It can be observed that there is a consistent margin of the strategic alternative S5 for the elements of S0, as factors that ensure the entrepreneurial development in disadvantaged mountainous areas and a consistent marking for the elements of WT type $(r=0,58)$, which indicates a positive perspective on the strategy that aims at the horizontal and vertical integration of the tourist entrepreneurship from disadvantaged mountainous areas both within the tourist sector and the other sectors of activity. For the strategic alternative S1 denotions generated by the value $r=-0,31$ are registered. Also, the evaluation of strategies aim at the interaction and development (S3 and S4) related to all the factors involved in analysis generated certain similitudes $(r=0,46)$ (Table 6).

\section{Conclusions}

The results of this analysis highlight the need to elaborate an integrated strategy for the entrepreneurship from the tourism in disadvantaged mountain areas which involve on the one hand the existent resources and on the other hand to capitalize the programmes with impact promoted by diverse organizations and national and international structures. Most problems of

Table 5 The values of strategic alternatives (Source: processing authors with K. Goepel v. 9.5.2012. software)

\begin{tabular}{|c|c|c|c|c|c|}
\hline & \multicolumn{5}{|c|}{ Strategic alternatives } \\
\hline & $\mathrm{S} 1$ & $\mathrm{~S} 2$ & $\mathrm{~S} 3$ & $\mathrm{~S} 4$ & S5 \\
\hline Total value & $0,009(5)$. & $0,187(4)$. & $0,349(3)$. & $0,517(2)$. & $1,284(1)$. \\
\hline
\end{tabular}


Table 6 The correlations of the evaluation of strategic alternatives (Source: processing authors with K. Goepel v. 9.5.2012. software)

\begin{tabular}{llllllll}
\hline Variables & Correlations & \multicolumn{7}{l}{} \\
\cline { 2 - 7 } & Total values & S1 & S2 & S3 & S4 & S5 & Factor $k$ \\
\hline Total values & 1.00 & $-0,10$ & $-0,32$ & $-0,49$ & $-0,54$ & $-0,56$ & $-0,25$ \\
S1 & $-0,10$ & 1.00 & $-0,18$ & $-0,29$ & $-0,42$ & $-0,61$ & $-0,31$ \\
S2 & $-0,32$ & $-0,18$ & 1.00 & $-0,20$ & $-0,64$ & $-0,76$ & $-0,33$ \\
S3 & $-0,49$ & $-0,29$ & $-0,20$ & 1.00 & 0,46 & $-0,38$ & $-0,48$ \\
S4 & $-0,54$ & $-0,42$ & $-0,64$ & 0,46 & 1.00 & $-0,47$ & $-0,61$ \\
S5 & $-0,56$ & $-0,61$ & $-0,76$ & $-0,38$ & $-0,47$ & 1.00 & 0,58 \\
Factor k & $-0,25$ & $-0,31$ & $-0,33$ & $-0,48$ & $-0,61$ & 0,58 & 1,00 \\
\hline
\end{tabular}

managing the entrepreneurial subsistence behaviour from disadvantaged mountain areas aim at fighting against their complexity through methods of optimizing the decisions related to costs and objectives. The optimization in this case aims at integrating the tourist sector both horizontally and vertically as a strategic alternative.

The great challenge entrepreneurs from the analysed disadvantaged mountainous areas are facing is represented by the need to ensure at the beginning a minimum of performance, and in this respect, the impact of a strategic integrated approach must be clearly understood. The results of this study can represent an useful support in the process of decisionmaking for validating the strategic alternatives, aiming at accelerating the transformation of the subsistence entrepreneurship into sustainable forms of business.

In fact, the adhesion of entrepreneurs to strategic versions and to a certain behaviour can have an effect of ascending harmonization, and from an operational point of view, the implementation of these strategies is a necessary option for those who want to achieve a level of performance. The identification of the disadvantaged areas of entrepreneurs' expectations, when it comes to the results of the implementation of some strategies, contributes to the focus of attention on those aspects that influence proactively the activities the firms.

Through this methodology, it was possible to connect entrepreneurs who do business in these areas and are interested in defining the framework, strategies and activities that can be done in order to remove obstacles related to the lack of a clear vision of consolidation and development in the field, or to the lack of infrastructure, respectively, the development of a sustainable relationship for the benefit of the area. This approach of using the AHP method with a group of entrepreneurs and identifying through its objective the specific alternatives for action is innovative for entrepreneurship in disadvantaged mountain areas.

Important aspects related to the way of involvement, resource allocation, functions that should serve all the categories involved and the results obtained could be identified through the assessments managed by entrepreneurs. Practically, the successful application of these elements demonstrated in other fields will lead to the definition, standardization and improvement of good practices by any entrepreneur, and especially to sustainable results over time. Thus, if the motivation and involvement of any interested party increase, the tourist potential in these areas will be properly and sustainably exploited.

A future challenge regarding the research for the entrepreneurial environment from disadvantaged mountain areas can be represented by the conjugated analysis of more variables 
that define the potential of regenerative or secondary existing resources in these areas and the use of the fuzzy logics associated with the AHP method in order to reduce the degree of uncertainty.

This paper brings new insights into the challenges and possible solutions for developing the disadvantaged mountainous areas by fostering the entrepreneurial spirit and initiatives and involving a wide range of stakeholders in a joint effort for creating a better business environment and increasing the quality of life for the whole local community.

\section{References}

Aronsson, L. (1994). Sustainable tourism systems: the example of sustainable rural tourism in Sweden. Journal of Sustainable Tourism, 2, 77-92.

Ayag, Z. (2005). A fuzzy AHP-based simulation approach to concept evaluation in a NPD environment. Journal IIE Transactions, 37(9), 827-842.

Bai, Y., Yao, L., Wei, T., Tian, F., Jin, D.-Y., Chen, L., \& Wang, M. (2020). Presumed asymptomatic carrier transmission of COVID-19. JAMA, 323(14), 1406.

Baldwin, R., \& Weder di Mauro, B. (2020). Introduction. In R. Baldwin \& B. Weder di Mauro (Eds.), Economics in the time of COVID-19 (pp. 1-30). CEPR Press.

Biggs, D., Hall, C. M., \& Stoeckl, N. (2012). The resilience of formal and informal tourism enterprises to disasters: Reef tourism in Phuket, Thailand. Journal of Sustainable Tourism, 20(5), 645-665.

Bramwell, B., \& Lane, B. (1993). Sustaining tourism: An evolving global approach. Journal of Sustainable Tourism, 1, 1-5.

Carey, S., Gountas, Y., \& Gilbert, D. (1997). Tour operators tour operators and destination sustainability. Tourism Management, 18(7), 425-432.

Cooper, I. (2006). Sustainable construction and planning: The policy agenda. Centre for Environmental Policy and Governance, London School of Economics.

Covin, J. G., \& Slevin, D. P. (1986). The development and testing of an organizational-level entrepreneurship scale. In R. Ronstadt, J. A. Hornaday, R. Peterson, \& K. H. Vesper (Eds.), Frontiers of entrepreneurship research (pp. 628-639). Babson College.

Coyle, G. (2004). The analytic hierarchy process. Practical strategy open access material AHP. Pearson Education Limited.

Crouch, D., Mccabe, S., Fennell, D., \& Dowling, R. (2003). Culture, consumption and ecotourism policies.

Eggers, F., Filser, M., Kraus, S., \& Málovics, E. (2014). The effect of financial resource availability on entrepreneurial orientation, customer orientation and firm performance in an international context: An empirical analysis from Austria and Hungary. Journal of East European Management Studies, 19(1), $7-30$.

Friel, M. (1999). Marketing practice in small tourism and hospitality firms. International Journal of Tourism Research, 1(2), 97-109.

Fyall, A., \& Garrod, B. (2005). Tourism marketing: A collaborative approach. Channel View Publications.

Garrod, B., \& Fyall, A. (1998). Beyond the rhetoric of sustainable tourism? Tourism Management, 19(3), $199-212$.

Getz, G., \& Timor, S. (2005). Stakeholder involvement in sustainable: Tourism balancing the voicesw. In G. Tourism (Ed.), Theobald (pp. 230-247). Elsevier.

Gösslin, S., \& Michael Hal, C. (2020). Pandemics, tourism and global change: A rapid assessment of COVID-19. Journal of Sustainable Tourism, 29, 1-20.

Hall, M. (2010). Crisis events in tourism: Subjects of crisis in tourism. Current Issues in Tourism, 13(5), 401-417.

Hardy, A., Beeton, R., \& Pearson, L. (2002). Sustainable tourism: An overview of the concept and its position in relation to conceptualisations of tourism. Journal of Sustainable Tourism, 10, 475-496.

Holden, A. (2003). In need of new environmental ethics for tourism. Annals of Tourism Research, 30, 94-108.

https://www.fonduri-structurale.ro/stiri/23550/100-de-miliarde-de-euro-pentrumentinerea-locurilor-demunca-si-sprijinirea-intreprinderilor-initiativa-sure-lansataastazi-de-comisia-europeana

https://covid19.geo-spatial.org/

https://www.onrc.ro/index.php/ro/statistici 
https://www.onrc.ro/index.php/ro/statistici?id=250

Statistical Yearbook of Romania. (2019). INS, București.

Inskeep, E. (1991). Tourism planning: An integrated and sustainable development approach. Van Nostrand Reinhold.

Kuščer, K., Mihalič, T., \& Pechlaner, H. (2016). Innovation, sustainable tourism and environments in mountain destination development: A comparative analysis of Austria, Slovenia and Switzerland. Journal of Sustainable Tourism, 25(4), 498-504.

Lane, B. (1994). What is rural tourism? Journal of Sustainable Tourism, 2(1-2), 7-21

Macbeth, J. (2005). Towards an ethics platform for tourism. Annals of Tourism Research, 32, 962-984.

MacDonald, R., \& Jolliffe, L. (2003). Cultural rural tourism - evidence from Canada. Annals of Tourism Research, 30(2), 307-322.

Murphy, P. (1983). Tourism as a community industry tourism management, no.4(3), pp. 180-193.

O'Reilly, A. (1986). Tourism carrying capacity: Concepts and issues. Tourism Management, 7, 254-258.

Pearce, W. (1994). The great environmental values debate. Environment and Planning a: Economy and Space, 26, 1329-1338.

Peters, M., \& Kallmuenzer, A. (2015). Entrepreneurial orientation in family firms: The case of the hospitality industry. Current Issues in Tourism, 21, 21-40.

Pigram, J., \& Jenkins, J. (1999). Outdoor recreation management. Routledge.

Roberts, L., \& Hall, D. (2001). Rural TOURISM and Recreation: Principles to practice. Cabi Publishing.

Saarinen, J. (2004). Destinations in change: The transformation process of tourist destinations. Tourist Studies, 4, 161-179.

Štrukelj, T., \& Šuligoj, M. (2014). Holism and social responsibility for tourism enterprise governance. Kybernetes, 43(3/4), 394-412.

Weaver, D. (2005). The distinctive dynamics of exurban tourism. International Journal of Tourism Research, 7(1), 23-33.

Wiklund, J., \& Shepherd, D. (2005). Entrepreneurial orientation and small business performance: A configurational approach. Journal of Business Venturing, 20(2005), 71-91.

www.azm.gov.ro

Publisher's Note Springer Nature remains neutral with regard to jurisdictional claims in published maps and institutional affiliations.

\title{
Authors and Affiliations
}

\author{
Nicoleta Cristache ${ }^{1} \cdot$ Ionica Soare $^{2} \cdot$ Marian Nastase $^{3} \cdot$ Valentin Marian Antohi $^{1}$ \\ Nicoleta Cristache \\ cristache.nicoleta@yahoo.de \\ Ionica Soare \\ soareionica@gmail.com \\ Marian Nastase \\ nastasem1@yahoo.com \\ 1 Department of Business Administration, Dunarea de Jos University, Galati, Romania \\ 2 Department of Economics, Dunarea de Jos University, Galati, Romania \\ 3 Department of Management, Bucharest University of Economic Studies, Bucharest, Romania
}

